\title{
Isolation and Molecular Characterization of Fowl Adenoviruses Associated with Inclusion Body Hepatitis-hydropericardium Syndrome in Broiler Chickens in Egypt
}

\author{
Mostafa G. Al Naguib ${ }^{1}$, Eman A. Morsy ${ }^{{ }^{*}}$, Mahmoud Samir ${ }^{2}$, Marwa S. Khattab ${ }^{3}$, Diaa G. Khelfa ${ }^{1}$, and Gomaa A. \\ Abdel-Alim ${ }^{1}$ \\ ${ }^{I}$ Department of Poultry Diseases, Faculty of Veterinary Medicine, Cairo University, Giza 12211, Egypt \\ ${ }^{2}$ Animal Health Institute, Agriculture Research Center, Giza 12211, Egypt \\ ${ }^{3}$ Department of Pathology, Faculty of Veterinary Medicine, Cairo University, Giza 12211, Egypt \\ *Corresponding author's Email: emananter@cu.edu.eg ; (DORCiD: 0000-0002-1906-5416
}

\begin{abstract}
Avian adenoviruses are an extremely diversified group of pathogens that recently triggering a variety of problems for poultry production. In particular, Inclusion Body Hepatitis-Hydropericardium Syndrome (IBH-HPS), which has been observed in broiler birds from 3 to 6 weeks of age and is associated with anemia, hemorrhagic disorders, hydropericardium, and high mortality. The disease has been reported worldwide, and recently it was reported in many Egyptian farms, causing severe economic losses. Therefore, the current study aimed to isolate, and genetically type the most common Adenovirus serotypes associated with this syndrome in Egyptian farms. A total of 50 broiler chicken farms (3-6 weeks old) located in different Egyptian governorates were examined. Macroscopically, the diseased flock revealed hydropericardium, enlarged friable livers with ecchymotic hemorrhages, and varying mortality rates (1 to $7.5 \%$ ). Histopathologically, severe diffuse necrotizing enteritis, hepatitis, pericarditis, and diffuse lymphoid depletion of the spleen were the most prominent lesions. Liver tissues and cloacal swabs were collected from all examined flocks for FAdVs detection by conventional polymerase chain reaction (PCR) targeting the L1 loop in the hexon gene. The PCR products were sequenced for typing of the detected viruses. It was found that 10 out of 50 flocks examined were PCR positive for FAdVs (20\%). Phylogenetic analysis of the sequenced genes revealed that the obtained viruses clustered with reference strains belonging to FAdV type D and E serotype 2, 11 , and 8a respectively. The isolation of both FAdV type D and FAdV type E were carried out on a primary cell culture chicken embryo liver cell (CEL) and the presence of these viruses was confirmed by PCR after the appearance of cytopathic effect (CPE). From this study, it could be concluded that both FAdVs types D and E are the most common adenoviruses circulating in poultry farms suffering from hydropericardium and inclusion body hepatitis.
\end{abstract}

Keywords: Broiler chicken, Chicken embryo liver cell, Fowl adenovirus, Hexon gene, Histopathology, Inclusion body hepatitis-hydropericardium syndrome, PCR

\section{INTRODUCTION}

Adenoviruses (AdVs) belong to the family Adenoviridae which are non-enveloped double-stranded DNA viruses. This family is distributed worldwide and has been recently classified into five genera, including Aviadenovirus, Mastadenovirus, Atadenovirus, Siadenovirus, and Ichtadenovirus (Hess, 2000). Virological analyses have enabled the division of the aviadenoviruses into five species of 12 serotypes (FADV-1 to FADV-8a and FADV-8b to FADV-11) based on genomic restriction digest patterns (FAdV-A to FAdV-E) (Hess, 2000). It has been shown that hepatitis inclusion body (IBH), hydropericardium syndrome (HPS), and gizzard erosion (GE) are the most common diseases associated with FadV infection in chickens (Mittal et al., 2014) The FAdVs' 12 serotypes have been associated with IBH outbreaks ( $\mathrm{Li}$ et al., 2018, Chen et al., 2018). However, FAdVs type D and E including serotypes; FAV-2, -3, -11 and FAV-6, -7, -8a, -8b respectively, are the most common relevant isolates (Schachner et al., 2018a).

Recently, outbreaks of IBH-HPS have hit several countries over the globe such as Japan (Nakamura et al., 2011), Malaysia (Mohamed Sohaimi et al., 2019), China (Li et al., 2018), India (Raj et al., 2018; Suohu et al., 2021) Spain (Oliver-Ferrando et al., 2017), Iran (Morshed et al., 2017), South Africa (Maartens et al., 2014) and Saudi Arabia (Hemida and Alhammadi 2017). The disease mortalities reach 5-10\% and may surge to 30\% if it is co-infected with other immunosuppressive agents, such as Chicken infectious anemia virus CIAV and Infectious bursal disease virus (IBDV) (McFerran and Smyth, 2000). Moreover, virulent HPS caused by FAdV serotype 4 (FAdV-4) leads to high mortality varying from 30-70\% (Mansoor et al., 2011; Schachner et al., 2018; Khan et al., 2019).

Grossly, the infected broilers revealed lesions in the liver and heart in the form of the enlarged, pale, friable liver with ecchymotic hemorrhages in addition to the accumulation of straw yellow-colored fluids in the pericardium (Schachner et al., 2018). Histologically, the most common findings were hepatitis, pancreatitis, nephrosis, thymic and bursal atrophy, and lymphoid depletion in the bursa and spleen. Basophilic and eosinophilic inclusion bodies of variable 
appearance were recorded in liver infected with IBH and rarely in the kidney. Moreover, HHS syndrome results in inflammatory and degenerative lesions mainly in the heart, kidneys, lungs, and intestine (Schachner et al., 2018).

Polymerase chain reaction (PCR) using primers specific to L1 loop as the most conserved region in hexon gene is used for characterization of FAdVs. Hexon is the main adenovirus protein and is typically used to detect FAdVs molecularly. Further FAdV typing was carried out using restriction enzyme length polymorphism (RFLP) and/or DNA sequencing (Hess, 2000) In Egypt, FAdVs outbreaks have been reported and confirmed by the sequence analysis of the viruses in collected samples (El-Tholoth and Abou El-Azm, 2019; Radwan et al., 2019; Elbestawy et al., 2020). Therefore, the current study was conducted for isolation, molecular characterization, typing, and histopathological picture of the most recent FAdVs circulating in broiler farms suffering from IBH/HPS in different Egyptian governorates.

\section{MATERIALS AND METHODS}

\section{Ethical approval}

The procedures for chicken handling were carried out in compliance with the applicable legislation of the Institutional Animal Care and Use Committee of the Faculty of Veterinary Medicine, University of Cairo, Egypt (VetCU24112020261).

\section{Sample collection}

The examined farms were in Egypt at Menofya, Menia, Giza, Beheira, and Fayum Governorates during 2019-2020. Liver tissues and cloacal swabs were collected from 50 broiler chicken farms ( 5 birds from each farm with a total number of 250 birds as 200 freshly dead and 50 birds with severe clinical signs that were euthanized) with the age range of 3-6 weeks for the detection of FAdVs. In addition, the bursa of Fabricius was collected for the detection of IBDV. The pooled cloacal swabs from each farm were dissolved in $1 \mathrm{~mL}$ normal saline with a $\mathrm{pH}$ of $7.4 \mathrm{containing}(1 \mathrm{mg} / \mathrm{mL})$ streptomycin $(50 \mu \mathrm{g} / \mathrm{mL})$ gentamycin and $(100,000 \mathrm{IE} / \mathrm{mL})$ penicillin. The liver and bursa tissue samples were collected in phosphate-buffered saline (PBS) then transported to the laboratory in an icebox. All samples were stored at $-20{ }^{\circ} \mathrm{C}$ for further processing and virus detection. In addition to the tissue specimens that were collected for histopathological examination.

\section{Preparation of collected samples}

The collected cloacal swabs samples were centrifuged at $700 \times \mathrm{g}$ for 10 minutes to clarify them. The collected supernatant was filtered by $0.2-\mu \mathrm{m}$ pore size syringe filters. The pooled liver samples ( 5 from each farm) were ground by sterile mortar and pistol. A $20 \%$ (w/v) suspension was prepared using sterile saline solution. Centrifugation of the suspensions was carried out for 20 minutes at 2000 rounds per minute (r.p.m.) Collected supernatants were preserved at $20^{\circ} \mathrm{C}$ till use. (Radwan et al., 2019)

\section{Histopathology}

Tissue specimens from the intestine, liver, heart, and spleen of chickens in suspected farms were fixed in $10 \%$ neutral buffered formalin. The tissues were dehydrated, cleared, embedded in paraffin, and sectioned by microtome into $4 \mu \mathrm{m}$ thick (Suvarna et al., 2018). Tissue sections were stained by hematoxylin and eosin stain, examined by a light microscope, and photographed by a digital camera (Olympus XC30, Tokyo, Japan).

\section{Virus detection and Identification by PCR \\ Extraction of nucleic acid}

The Genomic DNA isolation kit (Genedirex, Cat no. SN026-0100, Taiwan) was used to extract the total viral nucleic acid from $300 \mu \mathrm{L}$ of the supernatant following the manufacturer's instructions.

\section{Oligonucleotide primers}

In this study, the forward (HexL1-s) and reverse (HexL1-as) primers corresponding to a conserved area in the hexon gene L1 region were used (Raue et al., 2005) and are listed in Table 1.

Table 1. Hexon gene L1 region primers sequence

\begin{tabular}{lccc}
\hline Target gene/Amplicon size & Primer name & Nucleotide position & Sequence \\
\hline \multirow{2}{*}{ Hexon/589 bp } & Hex L1-s & $301-323$ & 5-ATGGGAGSACCTAYTTCGACAT-3 \\
\cline { 2 - 3 } & Hex L1-as & $890-868$ & 5-AAATTGTCCCKRAANCCGATGTA-3 \\
\hline
\end{tabular}




\section{Polymerase chain reaction}

Amplification of the target gene was achieved in a reaction volume of $25 \mu \mathrm{L}$ containing $5 \mu \mathrm{L}$ DNA template (congruent to $20 \%$ of the total reaction volume), $1 \mu \mathrm{L}$ of $10 \mu \mathrm{M}$ forward (HexL1-s) and the same of reverse (HexL1-as) primers, $12.5 \mu \mathrm{L} 2 \mathrm{X}$ One $\mathrm{PCR}^{\mathrm{TM}}$ polymerase chain reaction (PCR) master mix (One PCRTM, Genedirex; Cat. No. MB203-0100), and 5.5 $\mu \mathrm{L}$ nuclease-free water. One initial denaturation cycle of 4 minutes at $94^{\circ} \mathrm{C}$ was required for the PCR cycling profile, followed by 35 amplification cycles of 45 seconds for denaturation at $94^{\circ} \mathrm{C}, 45$ seconds for annealing at $51^{\circ} \mathrm{C}$, and 1 minute for the extension at $72^{\circ} \mathrm{C}$, and a final extension stage at $72^{\circ} \mathrm{C}$ for 10 minutes. In $1.5 \%$ agarose gel stained with ethidium bromide, the resulted amplified PCR products were electrophoresed and visualized under ultraviolet transillumination.

\section{Sequence and phylogenetic tree analysis}

The nucleotide sequence alignment was assembled and analyzed with representative reference to FAdVs strains' hexon gene sequences obtained from the GenBank database (http://www.ncbi.nlm.nih.gov/) using the NCBI BLAST server to confirm the identity with FAdVs strains. In BioEdit version 7.0.1.4 (Tom Hall, Ibis Biosciences, Carlsbad, CA, USA), sequences of FAdV hexon genes were downloaded from the NCBI GenBank and aligned using the Clustal W program. The subsequent phylogenetic analysis was carried out using Molecular Evolutionary Genetics Analysis version 6.0 constructed by the maximum likelihood approach based on the approximately 590-bp region corresponding to nucleotides 301-890 of the hexon gene and was used to demonstrate the clustering of the discrete species based on their hexon gene sequences. A similarity matrix has been created using the DNASTAR program (Lasergene, version 8.0).

\section{Detection of concurrent infection with infectious bursal disease virus and chicken infectious anemia virus by conventional PCR}

Detection of accompanied infections with infectious bursal disease virus (IBDV) and chicken infectious anemia virus (CIAV) was performed using the extracted viral DNA/RNA from the liver for CIAV and bursa of Fabricius tissues for IBDV from Adenovirus positive cases by conventional PCR assay as previously reported by Metwally et al. (2009) and Elbestawy et al. (2020).

\section{Virus isolation on primary chicken embryo liver cells Virus preparation}

The supernatant of the collected FAdVs positive by PCR samples was passed through syringe filters with $0.2-\mu \mathrm{m}$ pore size. Primary chicken embryo liver (CEL) cell was obtained from the liver of 15-day-old SPF embryonated chicken eggs (ECE) (Kumar et al., 2003).

Virus propagation

Flasks containing complete monolayer were washed two successive times with serum-free medium and inoculated with $0.1 \mathrm{~mL}$ of the forementioned supernatant. For virus adsorption onto cells the inoculated flasks were incubated at $37^{\circ} \mathrm{C}$ for one hour then a maintenance medium containing $2 \%$ fetal bovine serum (FBS) was added. Daily observation of the inoculated cells for CPE was done using an inverted microscope during the first three successive days postinoculation (pi). After obvious CPEs development, the flasks were harvested three times by repeated freezing and thawing before centrifugation at $216 \mathrm{x}$ g for 10 minutes. Viral fluid was collected and stored at $-20^{\circ} \mathrm{C}$ for further process. Complete monolayers were prepared for subsequent passage and inoculated with $0.1 \mathrm{~mL}$ of viral fluid. However, one monolayer was left uninoculated and was used as control cells (Mansoor et al., 2011)

\section{Confirmation of fowl adenoviruses in cell culture by PCR}

After the appearance of CPE in cell culture, the presence of FAdVs was confirmed by conventional PCR.

\section{RESULTS}

\section{Clinical cases and gross lesions}

During 2019-2020, 50 broiler flocks suffering from hydropericardium IBH syndrome in different governorates in Egypt were examined. The distribution and mortalities are summarized in Table 2 and Figure 1. Clear postmortem lesions in the form of a clear straw yellow serous fluid accumulation in the pericardium, swollen livers with necrotic foci, and petechial hemorrhages were observed (Figure 2).

\section{Histopathological findings}

Microscopy of the intestine showed severe diffuse necrotizing enteritis which was either acute or chronic according to the stage of infection. Intranuclear basophilic inclusion bodies were seen in infiltrating cells (Figure 3a, b, c). The hepatic lesions varied from vacuolation and necrobiotic changes to massive necrosis and dissociation of hepatocytes at the periphery of hepatic lobules with the presence of intranuclear eosinophilic inclusion bodies (Figure $3 \mathrm{~d}$, e, f). The heart had endothelial cell hypertrophy of blood vessels, pericarditis, degeneration of muscle bundles, necrotic foci with 
mononuclear cells infiltration, edema, heterophils infiltration in between muscle bundles, and perivascular mononuclear cells infiltration in addition to the presence of intranuclear inclusion bodies in infiltrating leukocytes (Figure $3 \mathrm{~g}$, h, i). The spleen showed lymphocytolysis, lymphoid depletion, and reticular hyperplasia. Prominent intranuclear eosinophilic inclusion bodies were observed in lymphocytes and reticular cells (Figure 3j, k, l).

Virus detection by PCR

Ten out of 50 examined flocks were positive for FAdVs (20\%). Positive samples with a DNA length fragment of $590 \mathrm{bp}$ were detected from cloacal swabs and liver tissues (Figure 4). The percentage of positive flocks from different governorates is listed in Table 2. In addition, all FAdVs positive samples were negative for IBDV and CIAV by -PCR.

Table 2. Distribution of fowl adenovirus infections and mortality percentage in broiler flocks at different governorates in Egypt

\begin{tabular}{|c|c|c|c|c|c|c|}
\hline \multirow[b]{2}{*}{ Governorate } & \multirow{2}{*}{$\begin{array}{c}\text { Number of } \\
\text { investigated } \\
\text { farms }\end{array}$} & \multirow[b]{2}{*}{$\begin{array}{c}\text { Number of } \\
\text { Positive flocks }\end{array}$} & \multicolumn{2}{|c|}{ Type of sample } & \multirow{2}{*}{$\begin{array}{c}\text { Mortality } \\
\text { (During the } \\
\text { disease course, } \\
\% \text { ) }\end{array}$} & \multirow{2}{*}{$\begin{array}{c}\text { Percentage of } \\
\text { positive flocks } \\
\text { Governorate }\end{array}$} \\
\hline & & & Pooled livers & $\begin{array}{c}\text { Pooled cloacal } \\
\text { swabs }\end{array}$ & & \\
\hline \multirow{2}{*}{ Menofya } & \multirow{2}{*}{7} & \multirow{2}{*}{2} & Positive & Negative & 7.5 & \multirow[b]{2}{*}{28.5} \\
\hline & & & Positive & Negative & 6.6 & \\
\hline \multirow{3}{*}{ Fayoum } & \multirow{3}{*}{10} & \multirow{3}{*}{3} & Negative & Positive & 3 & \multirow{3}{*}{30} \\
\hline & & & Positive & Negative & 5 & \\
\hline & & & Negative & Positive & 2 & \\
\hline \multirow{2}{*}{ Menia } & \multirow{2}{*}{11} & \multirow{2}{*}{2} & Negative & Positive & 4 & \multirow[b]{2}{*}{18.1} \\
\hline & & & Negative & Positive & 1 & \\
\hline Giza & 10 & 1 & Negative & Positive & 3.5 & 10 \\
\hline Dakhlya & 6 & 1 & Negative & Positive & 4 & 16.6 \\
\hline Behera & 6 & 1 & Negative & Positive & 2 & 16.6 \\
\hline Total & 50 & 10 & 3 & 7 & 38.6 & \\
\hline
\end{tabular}

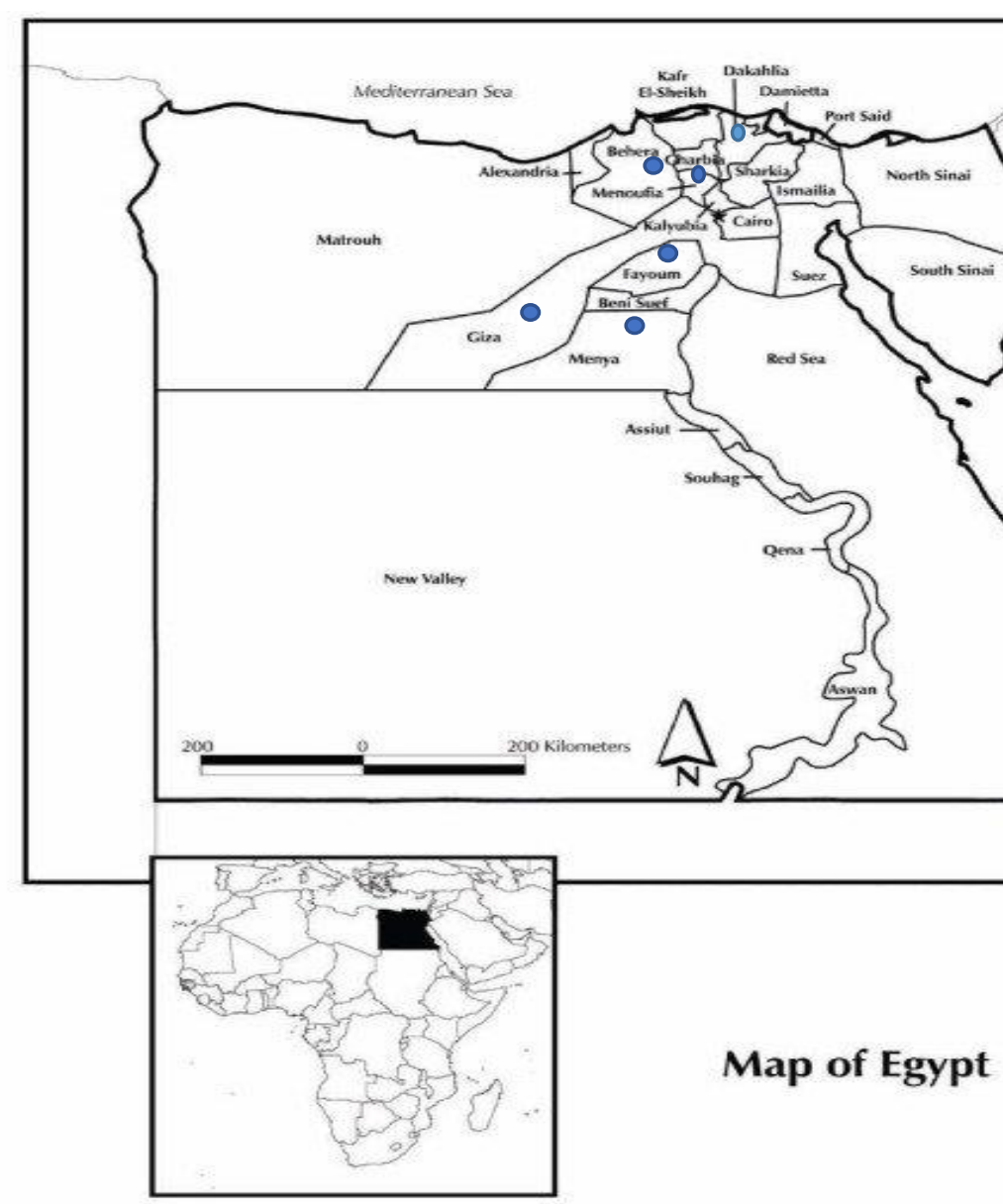

Figure 1. Fowl adenoviruses distribution in broiler chickens at different Egyptian governorates (Blue points) 


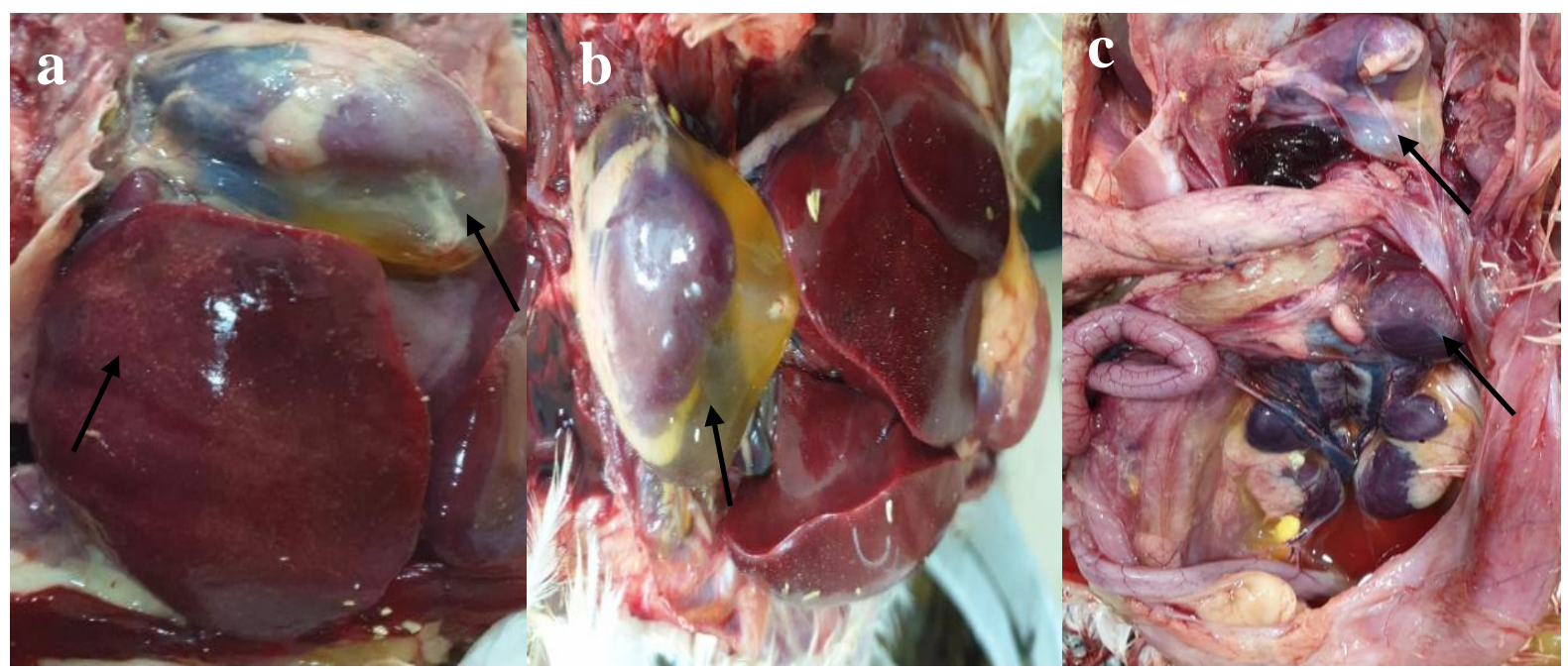

Figure 2. Gross pathology of naturally infected chickens with Inclusion Body Hepatitis-Hydropericardium Syndrome. a and b: Hydropericardium with necrosis and enlargement of the liver. c: hydropericardium and nephrosis.

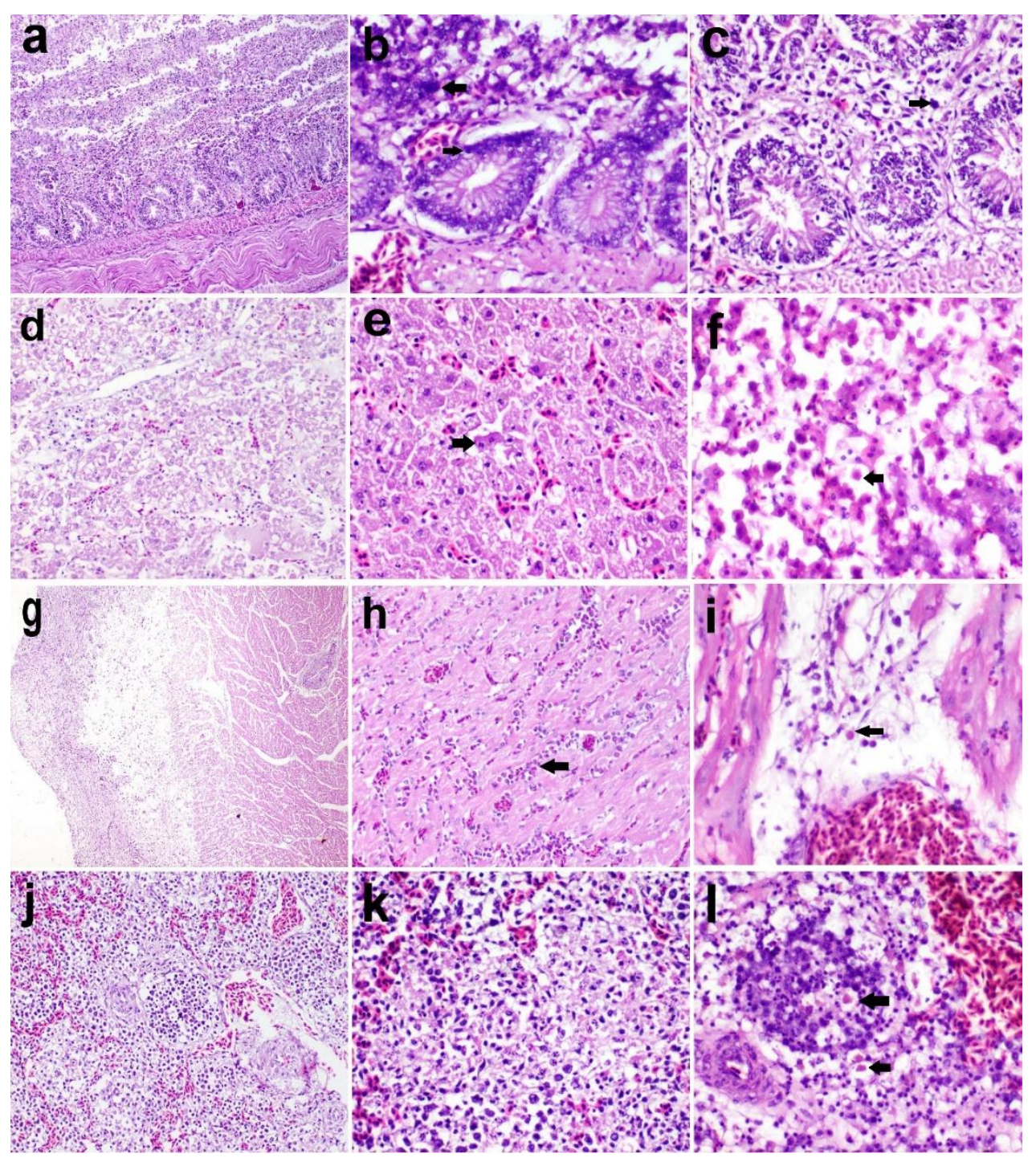

Figure 3. Histopathology of naturally infected chickens with Inclusion body hepatitis-hydropericardium syndrome. a-c: Chicken intestine, a: Chronic diffuse necrotizing enteritis (X100), b: Basophilic Intranuclear inclusion body (IN IB) (arrows) in the glandular epithelium, c: karyorrhexis in the glandular epithelium (X400). d-f: Chicken liver, d: Severe diffuse vacuolar degeneration of hepatocytes (X200), e: Necrobiotic changes and karyorrhexis of hepatocytes (arrow) (X400), f: Dissociation of hepatocytes with eosinophilic IN IB (arrow) (X400), g: Severe diffuse pericarditis (X100), h: Heterophils infiltration between muscle bundles (X200), i: Perivascular edema and perivascular mononuclear cells infiltration with eosinophilia in ib (arrow) (x400), j-l: Chicken spleen, $\mathbf{j}$ : Moderate diffuse depletion of white pulp (X200), k: Lymphocytolysis with small basophilic IN IB (arrow) (X400), l: Large eosinophilic IN IB in lymphocytes (arrow, X400, H \& E stain). 


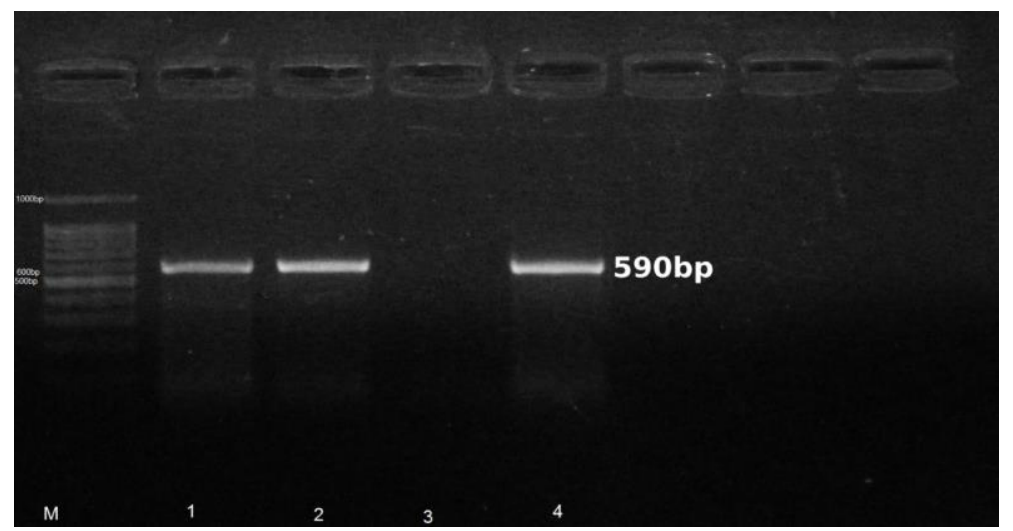

Figure 4. Visualization of 590-bp PCR product of hexon gene of FAdVs by agarose gel electrophoresis (1.5\%) after staining with ethidium bromide. Lane M: 100bp DNA ladder, Lanes 1, 2: positive samples, Lane 3: Control negative, Lane 4: Control positive.

\section{Phylogenetic analysis}

A phylogenetic tree was created based on our sequences, and the reference strain's hexon gene sequences from different countries (Egypt, France, Brazil, Malaysia, China, Japan, and India) that were available on the GenBank (Table 3 ) to confirm the clustering of the various species. Phylogenetic analysis showed that the isolated FAdVs were classified as Fowl adenovirus type D serotype FAdV-2 and FAdV-11 in addition to Fowl adenovirus serotype FAdV-8a type E (Figure 5). Inter and intra-species analyses of genetic distance among the obtained sequences and other 14 aligned sequences available in the NCBI GenBank database of FAdV were performed (Figure 6). The genetic identity of FAdVstype D had a high sequence homology (93.98\% similarity) with the Indian FAdV type D, serotype 2 strains (MK816406.1 and MF770580.1) which previously has been isolated from liver tissues of broilers. On the other hand, the isolated FAdVs-type E viruses had a high sequence homology (99\% similarity) with the Egyptian FAdV type E, serotype 8a (KT781516.1 and KT781517.1) that were isolated from cloacal swab samples of broiler chickens as illustrated in Figure 6. The partial hexon gene sequences of the two strains of FAdV-D and the FADV-E strain were submitted to the NCBI GenBank under accession numbers (MT386509.1, MT356630.1, MT893206.1, and MW847902), respectively (Table 3).

\section{Virus isolation on cell culture}

Three positive samples, including FAdV-D serotype 2, FAdV-D serotype 11, and FAdV-E (serotype-8a), were passaged on CEL. Different degrees of CPE on cell culture were observed in the inoculated cells as early as $24 \mathrm{hr}$ post inoculation after first passage with type E virus and after second passage from type D virus (Figure 7).

Table 3. Reference isolates of Fowl aviadenovirus serotypes on GenBank and isolates of the current study

\begin{tabular}{|c|c|c|c|c|c|}
\hline Accession No. & Country & Host & Sample type & Strain & Collection date \\
\hline MT708028.1 & France & $\begin{array}{l}\text { Numida meleagri } \\
\text { guinea fowl }\end{array}$ & Pancreas & $\begin{array}{l}\text { Fowl aviadenovirus } \mathrm{A} \\
\text { (fowl adenovirus type } 1 \text { ) }\end{array}$ & 2018 \\
\hline KT781516.1 & Egypt & Chicken & Cloacal swabs & Fowl adenovirus $8 \mathrm{a}$ & 2015 \\
\hline KT781517.1 & Egypt & Chicken & Cloacal swabs & Fowl adenovirus 8a & 2015 \\
\hline MN453821.1 & Brazil & Gallus gallus with RSS & Intestinal content & Fowl adenovirus 8a & 2010 \\
\hline MT127100.1 & Malaysia & SPF Embryonated Chicken Eggs & - & Fowl adenovirus $8 \mathrm{~b}$ & 2017 \\
\hline MT127101.1 & Malaysia & SPF Embryonated Chicken Eggs & - & Fowl adenovirus $8 \mathrm{~b}$ & 2017 \\
\hline MT561444.1 & Malaysia & SPF Embryonated Chicken Eggs & $\begin{array}{l}\text { Chicken embryo } \\
\text { liver cell }\end{array}$ & Fowl aviadenovirus E & 2019 \\
\hline MT233532.2 & Malaysia & Broiler & $\begin{array}{l}\text { Chicken embryo } \\
\text { liver cell }\end{array}$ & Fowl aviadenovirus E & 2017 \\
\hline MK816406.1 & India & Gallus gallus & - & Fowl aviadenovirus D & 2017 \\
\hline MF770580.1 & India & Poultry & Liver & Fowl aviadenovirus D & 2016 \\
\hline MH492324.1 & Japan & layer chickens & Oviducts & Fowl aviadenovirus 4 & 2014 \\
\hline MH159176.1 & China & Chicken & - & Fowl aviadenovirus 4 & 2008 \\
\hline MH159177.1 & China & Chicken & - & Fowl aviadenovirus 4 & 2017 \\
\hline MT386509.1 & Egypt & Broiler chickens & Liver tissue & $\begin{array}{l}\text { Fowl aviadenovirus D } \\
\text { Serotype }\end{array}$ & $\begin{array}{c}2019 \\
\text { Current study }\end{array}$ \\
\hline MT893206.1 & Egypt & Broiler chickens & Liver tissue & $\begin{array}{l}\text { Fowl aviadenovirus D } \\
\text { Serotype }\end{array}$ & $\begin{array}{c}2019 \\
\text { Current study }\end{array}$ \\
\hline MT356630.1 & Egypt & Broiler chickens & Liver tissue & $\begin{array}{l}\text { Fowl aviadenovirus D } \\
\text { Serotype }\end{array}$ & $\begin{array}{c}2019 \\
\text { Current study }\end{array}$ \\
\hline MW847902 & Egypt & Broiler chickens & Cloacal swabs & Fowl aviadenovirus E 8a & $\begin{array}{c}2019 \\
\text { Current study }\end{array}$ \\
\hline
\end{tabular}




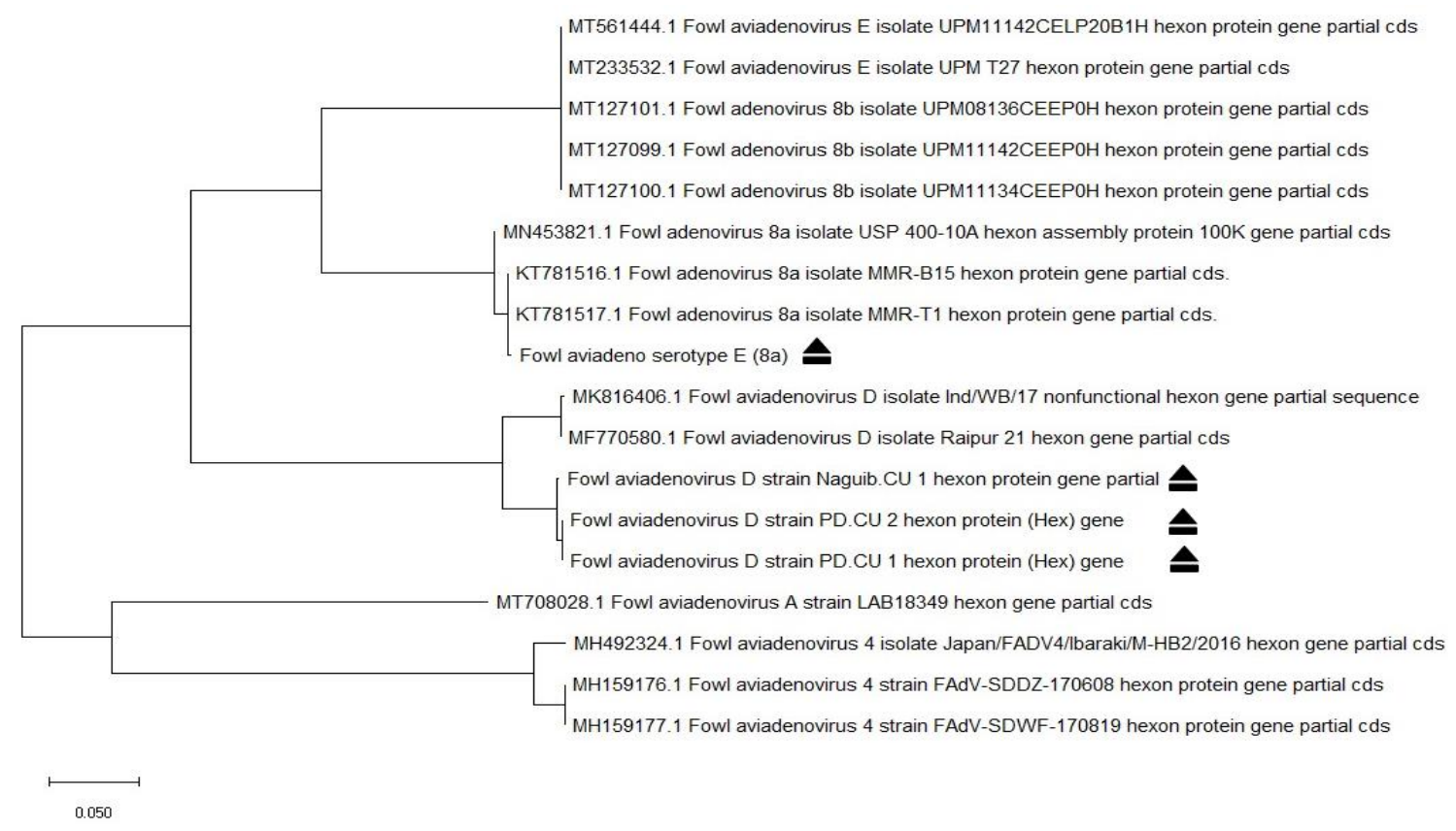

Figure 5. Phylogenetic tree of the partial hexon gene fragment nucleotide sequences of our isolates and reference strains from the GenBank (accession number of the reference strain's hexon gene sequences were mentioned beside each nucleotide sequence)

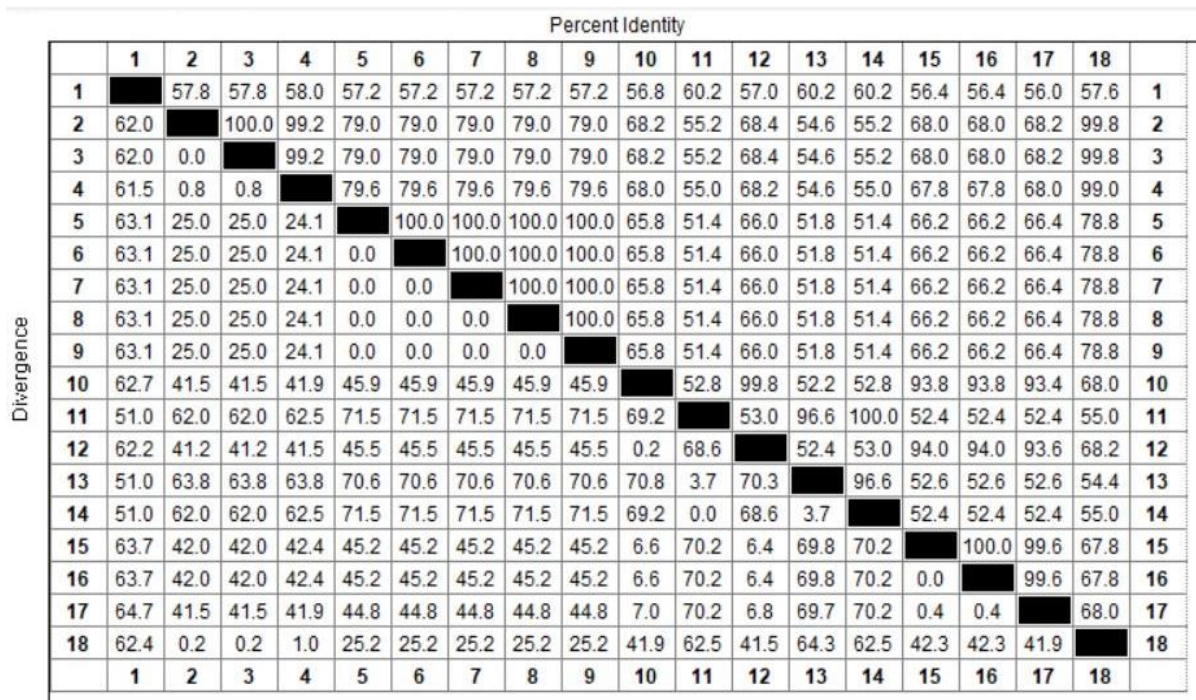

MT708028.1_Fowl_aviadenovirus_A_strain_ KT781516.1_Fowl_adenovirus_8a_isolate_M KT781517.1_Fowl_adenovirus_8a_isolate_M MN453821.1_Fowl_adenovirus_8a_isolate_U MT127099.1_Fowl_adenovirus_8b_isolate_U MT127100.1_Fowl_adenovirus_8b_isolate_U MT127101.1_Fowl_adenovirus_8b isolate_U MT561444.1_Fowl_aviadenovirus_E_isolate MT233532.1_Fowl_aviadenovirus_E_isolate 17_nonfunctional_hexon_gene_partial_seq MH159177.1_Fowl_aviadenovirus_4_strain_ MF770580.1_Fowl_aviadenovirus_D_isolate 2016_hexon_gene_partial_cds MH159176.1_Fowl_aviadenovirus_4_strain_ MT386509.1 МT 356630.1 MT83206.1 MW847902

Figure 6. Similarity (percent identity) of L1 loop of the hexon gene sequences and their amino acids translate of FAV from broiler chickens in Egypt (representing numbers 15, 16, 17, and 18) as compared with the most similar reference sequences (GenBank).
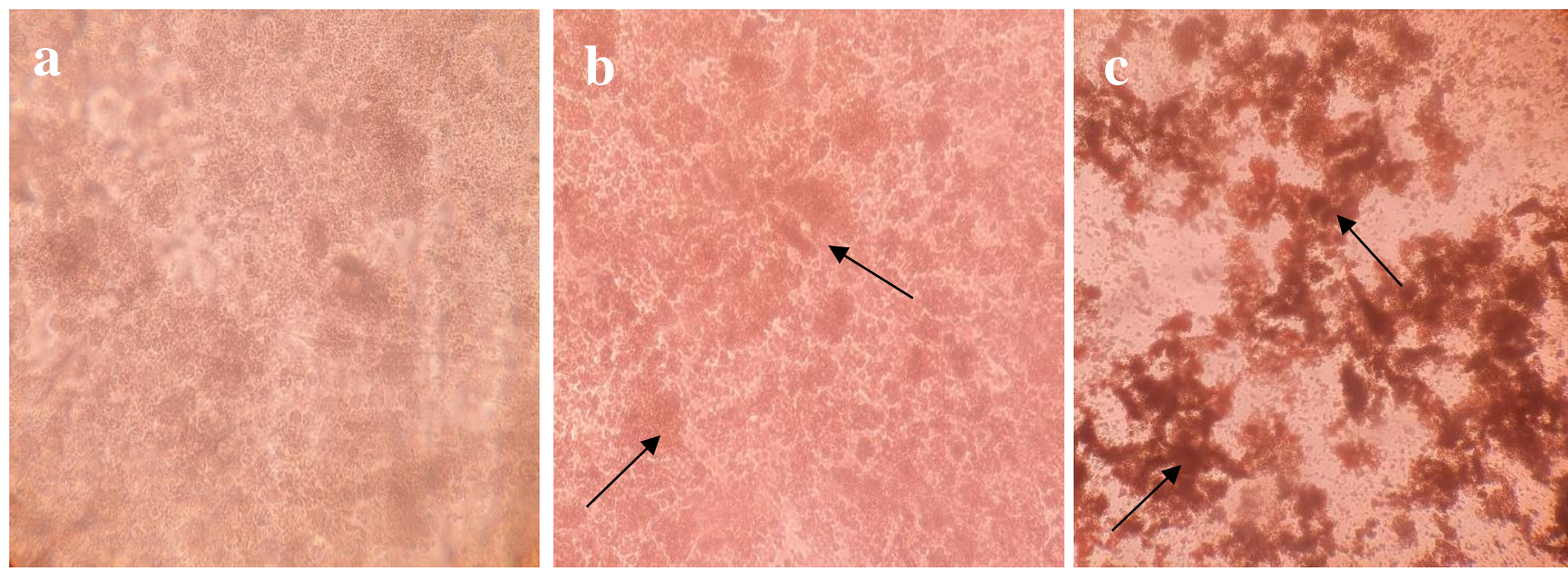

Figure 7. Different stages of growth of FAdV on chicken embryo liver. a: Spindle shape of the liver cells. b: Cytopathic effect after 24 hours appeared as (small areas of cell death). c: large areas of focal cell death with the beginning detachment of the cells (CPE after 2 dpi). 
Over the past decade, inclusion body hepatitis-hydropericardium syndrome (IBH-HPS) has gained importance as one of the pivotal vertically transmitted diseases in broiler chickens that tackle the growing poultry industry all over the globe (Hafez, 2011; Shah et al., 2017; Schachner et al., 2018). In many countries, especially in Egypt, FAdV is considered to be the main pathogen within the first five weeks of broilers causing significant economic losses (Radwan et al., 2019).

In the current study, the examined flocks grossly revealed hepatic enlargement with pale pinpointed foci, liver ecchymotic hemorrhage, and straw-yellow fluid in pericardium up to $15 \mathrm{~mL}$. In addition, nephrosis and enlargement of the spleen were noticed. These lesions resemble IBH-HPS findings previously described by (McFerran and Smyth, 2000; Hafez, 2011).

These gross lesions and mortality were attributed to the replication of FAVS in liver cells and extensive hepatic damage which leads to a decrease in the colloid osmotic pressure and increase of blood vessel permeability with a massive accumulation of fluid around the heart and finally cardiac tamponade and death (Niu et al., 2019). Histologically, degenerative and inflammatory lesions were recorded in the intestine, liver, pericardium, and heart with the presence of eosinophilic intranuclear inclusion bodies similar to previous studies (Steer et al., 2015; Niu et al., 2019; Radwan et al., 2019c).

Although it was assumed before that the heart was not the target organ of FAdV-4, severe pericarditis and heterophils infiltration were the most prominent lesions observed in the heart in the present study in addition to interstitial edema and widening of the gap between myocardial fibers (Niu et al., 2019).

Mortalities in the positive FAdVs tested flocks had a wide range from 1 to $7.5 \%$. Variation in broilers mortalities due to IBH was recorded in many countries including Canada (Ojkic et al., 2008), Japan, Iran (Rahimi and Minoosh Siavosh Haghighi, 2015), China (Changjing et al., 2016), and Egypt (Hafez, 2011; Radwan et al., 2019).

IBDV and CIAV have been reported as common co-infection of FAdVs positive flocks which exacerbate the death rates as described by (Elbestawy et al., 2020). Despite this, there have been reports that IBH can cause mortality even when no other infective agent is present (Mohamed et al., 2018). Neither CIAV nor IBDV was detected in all FAdVs positive flocks in the current study. Therefore, FAdVs could be the primary pathogen responsible for mortality in the examined flocks.

Nevertheless, the clinical signs, post mortem lesions, and histopathology were highly indicative for FAdV infection, molecular detection by PCR assay was used to confirm the disease as previously reported earlier by (Raue et al., 2005; Günes et al., 2012; Mittal et al., 2014). By using the conventional PCR technique, only 10 out of 50 examined flocks were positive $(20 \%)$ and this low percentage of virus detection by PCR may be interpreted by the usage of a conventional PCR in viral recognition, which is less sensitive in comparing with a real-time PCR (Günes et al., 2012). Only three farms were positive for liver tissue samples, and seven farms were positive for cloacal swabs. Consequently, sampling by cloacal swabs is considered better than liver tissues for detection of FAdv in broiler chicken, and this finding agrees with that recorded by (Radwan et al., 2019). In addition, FAdV virus isolation was carried out using primary CEL and cytopathic effects were noticed after 24 hours of virus inoculation in the form of cell rounding and small focal cells' areas detachment from the surface. Similar CPE in CEL of FAdVs was previously described by(Soumyalekshmi et al., 2014; Mohamed Sohaimi et al., 2019).

Further typing of the isolated viruses indicated that they are belonged to FAdV-type D serotypes 2 and 11 , in addition to FAV- type E serotype 8a. The obtained sequences were clustered with fowl Adenoviruses strains isolated from Europe, Brazil, Malaysia, China, Japan, and India. Many countries all over the world reported detection of FAdV-D including Canada (Ojkic et al., 2008), South Africa (Maartens et al., 2014), China (Changjing et al., 2016), Poland (Niczyporuk, 2016), Lebanon (Shaib et al., 2017), Saudi Arabia (Mohamed et al., 2018) and Egypt (El-Tholoth and Abou El-Azm, 2019; Elbestawy et al., 2020). In addition, Radwan et al., 2019 previously detected two strains of serotype FAdV-8a (FAdV-E) in Egyptian chicken farms during 2015. These viruses had a high sequence homology with the viruses isolated during the current study that throws light on the nature, and resistance of adenoviruses over time.

Detection and characterization of FAdVs serotypes play a major role in epidemiologic studies of the disease spread, the development of preventative measures, and the application of vaccination programs. The current study spots light on the distribution and molecular characterization of FAdVs from cases of IBH-HPS that have been recently increased in broiler chicken flocks in Egypt and resulted in significant economic losses to the poultry industry.

\section{CONCLUSION}

In conclusion, the necessity to update the recent situation of Adenoviruses associated with hydropericardium syndrome in different broiler farms in many governorates in Egypt prompts us to conduct this study. Virus detection by PCR and sequence analysis indicated that both type D and type E adenovirus are the most common adenovirus associated with this syndrome in broiler farms in different governorates in Egypt. Further study will be conducted to study the pathogenicity of these isolated viruses in broiler chickens. 
Ethical considerations

Ethical issues including plagiarism, consent to publish, misconduct, data fabrication and/or falsification, double publication and/or submission, and redundancy have been checked by the authors.

\section{Competing interests}

The author has no conflict of interest.

\section{Authors' contributions}

DGK, MGA, EAM, and GAA contributed to the design of the study, sample collection, isolation, identification of the virus, sequencing, and sequence analysis. MS carried out virus isolation, identification, and titration on cell culture. MSK carried out the histopathological examination. All authors drafted the manuscript and participated in the subsequent discussions and revisions of the entire text. All authors read and approved the results and final manuscript.

\section{Acknowledgments}

The authors would like to thank the Poultry diseases department, Faculty of Veterinary Medicine, Cairo University, Egypt for its assistance and support. This work did not receive any specific grant from any funding agencies.

\section{REFERENCES}

Changjing L, Haiying L, Dongdong W, Jingjing W, Youming W, Shouchun W, Jida L, Ping L, Jianlin W, Shouzhen X et al. (2016). Characterization of fowl adenoviruses isolated between 2007 and 2014 in China. Veterinary microbiology, 197: 62-67. DOI: https://www.doi.org/10.1016/j.vetmic.2016.11.005

Chen Z, Shi S, Qi B, Lin S, Chen C, Zhu C, and Huang YJ (2018). Hydropericardium syndrome caused by fowl adenovirus serotype 4 in replacement pullets. Journal of Veterinary Medical Science, 81 (2): 245-251. DOI: https://www.doi.org/10.1292/jvms.18-0168

Elbestawy AR, Ibrahim M, Hammam H, Noreldin AE, Bahrawy AE, and Ellakany HF (2020). Molecular Characterization of Fowl Adenovirus D Species in Broiler Chickens with Inclusion Body Hepatitis in Egypt. Alexandria Journal of Veterinary Sciences, 64: 110-116. DOI: https://www.doi.org/10.5455/ajvs.74411

El-Tholoth M, and Abou El-Azm KI (2019). Molecular detection and characterization of fowl adenovirus associated with inclusion body hepatitis from broiler chickens in Egypt. Tropical Animal Health Production, 51: 1065-1071. DOI: https://www.doi.org/10.1007/s11250-018-01783-0

Günes A, Marek A, Grafl B, Berger E, and Hess M (2012). Real-time PCR assay for universal detection and quantitation of all five species of fowl adenoviruses (FAdV-A to FAdV-E). Journal of Virological Methods, 183: 147-153. DOI: https://www.doi.org/10.1016/j.jviromet.2012.04.005

Hafez HM (2011). Avian adenoviruses infections with special attention to inclusion body hepatitis/hydropericardium syndrome and egg drop syndrome. Pakistan Veterinary Journal, 31: 85-92. DOI: http://www.dx.doi.org/10.17169/refubium-18486

Hemida M, and Alhammadi M (2017). Prevalence and molecular characteristics of fowl adenovirus serotype 4 in eastern Saudi Arabia. Journal of Veterinary and Science, 41: 506-513. DOI: https://www.doi:10.3906/vet-1612-19

Hess MJAP (2000). Detection and differentiation of avian adenoviruses: A review. Avian Pathology, 29: 195-206. DOI: https://www.doi.org/10.1080/03079450050045440

Khan AA, Sabri AN, Mansoor MK, and Hussain I (2019). Hydropericardium syndrome in Pakistan: A review. World's Poultry Science Journal, 61: 647-654. DOI: https://www.doi.org/10.1079/WPS200576

Kumar R, Chandra R, and Shukla S (2003). Isolation of etiological agent of hydropericardium syndrome in chicken embryo liver cell culture and its serological characterization. Indian Journal of Experimental Biology, 31: 821-826. Available at: http://hdl.handle.net/123456789/17161

Li L, Wang J, Chen P, Zhang S, Sun J, and Yuan W (2018). Pathogenicity and molecular characterization of a fowl adenovirus 4 isolated from chicken associated with IBH and HPS in China. BMC Veterinary Research, 14: 400. DOI: https://www.doi.org/10.1079/WPS200576

Maartens LH, Joubert HW, Aitchison H, and Venter EH (2014). Inclusion body hepatitis associated with an outbreak of fowl adenovirus type 2 and type $8 \mathrm{~b}$ in broiler flocks in South Africa. Journal of the South African Veterinary Association, 85: 1-5. DOI: https://www.doi.org/10.4102/jsava.v85i1.1146

Mansoor MK, Hussain I, Arshad M, and Muhammad G (2011). Preparation and evaluation of chicken embryo-adapted fowl adenovirus serotype 4 vaccine in broiler chickens. Tropical Animal Health Production, 43: 331-338. DOI: https://www.doi.org/10.1007/s11250-010-9694-Z

Mcferran J, and Smyth J (2000). Avian adenoviruses. Revue Scientifique et Technique (International Office of Epizootics), 19: 589-601. PMID: 10935281. Available at: https://www.oie.int/doc/ged/D9436.PDF

Metwally A, Yousif A, Shaheed I, Mohammed W, Samy A, and Reda I (2009). Re-emergence of very virulent IBDV in Egypt. International Journal of Virology, 5: 1-17. Available at: https://scialert.net/abstract/?doi=ijv.2009.1.17

Mittal D, Jindal N, Tiwari AK, and Khokhar RS (2014). Characterization of fowl adenoviruses associated with hydropericardium syndrome and inclusion body hepatitis in broiler chickens. Virus disease, 25: 114-119. DOI: https://www.doi.org/10.1007/s13337-013-0183-7

Mohamed MHA, El-Sabagh IM, Abdelaziz AM, Al-Ali AM, Alramadan M, Lebdah MA, Ibrahim AM, and Al-Ankari AS (2018). Molecular characterization of fowl aviadenoviruses species D and E associated with inclusion body hepatitis in chickens and falcons indicates possible cross-species transmission. Avian Pathology, 47: 384-390. DOI: https://www.doi.org/10.1080/03079457.2018.1457769

Mohamed Sohaimi N, Bejo MH, Omar AR, Ideris A, and Mat Isa N (2019). Molecular characterization of fowl adenovirus isolate of Malaysia attenuated in chicken embryo liver cells and its pathogenicity and immunogenicity in chickens. PLoS One, p. 14. DOI: https://doi.org/10.1371/journal.pone.0225863

Morshed R, Hosseini H, Langeroudi AG, Fard MHB, and Charkhkar S (2017). Fowl adenoviruses D and E cause inclusion body hepatitis outbreaks in broiler and broiler breeder pullet flocks. Avian Diseases, 61: 205-210. DOI: https://www.doi.org/10.1637/11551-120516-Reg.1

Nakamura K, Mase M, Yamamoto Y, Takizawa K, Kabeya M, Wakuda T, Matsuda M, Chikuba T, Yamamoto Y, Ohyama T et al. (2011). Inclusion body hepatitis caused by fowl adenovirus in broiler chickens in Japan, 2009-2010. Avian Diseases, 55: 719-723. DOI: https://www.doi.org/10.1637/9813-052511-Case.1 
Niczyporuk JS (2016). Phylogenetic and geographic analysis of fowl adenovirus field strains isolated from poultry in Poland. Archives of Virology, 161: 33-42. DOI: https://www.doi.org/10.1007/s00705-015-2635-4

Niu Y, Sun Q, Liu X, and Liu S (2019). Mechanism of fowl adenovirus serotype 4-induced heart damage and formation of pericardial effusion. 98: 1134-1145. DOI: https://doi.org/10.3382/ps/pey485

Ojkic D, Martin E, Swinton J, Vaillancourt JP, Boulianne M, and Gomis S (2008). Genotyping of Canadian isolates of fowl adenoviruses. Avian Pathology, 37: 95-100. DOI: https://www.doi.org/10.1080/03079450701805324

Oliver-Ferrando S, Dolz R, Calderón C, Valle R, Rivas R, Pérez M, Biarnés M, Blanco A, Bertran K, and Ramis A (2017). Epidemiological and pathological investigation of fowl aviadenovirus serotypes 8b and 11 isolated from chickens with inclusion body hepatitis in Spain (2011-2013). Avian Pathology, 46: 157-165. DOI: https://www.doi.org/10.1080/03079457.2016.1232477

Radwan MM, El-Deeb AH, Mousa MR, El-Sanousi AA, and Shalaby MA (2019). First report of fowl adenovirus 8a from commercial broiler chickens in Egypt: Molecular characterization and pathogenicity. Poultry Science, 98: 97-104. DOI: https://www.doi.org/10.3382/ps/pey314

Rahimi M and Minoosh Siavosh Haghighi Z. (2015). Adenovirus-like inclusion body hepatitis in a flock of broiler chickens in Kermanshah province, Iran. Veterinary Research Forum. 6(1):95-98. Available at: https:// www.ncbi.nlm.nih.gov/pmc/articles/PMC4405693/pdf/vrf-6-095.pdf

Raj Narayan Trivedi, Rajesh Kumar, Mamta Metwal, Amir Showkat Khan, Akanksha Tiwari, Garima Panday and Avadhesh Kumar. (2018). Epidemiological Observations on Some Natural Outbreaks of Inclusion Body Hepatitis-Hydropericardium Syndrome (IBH-HPS) in Domestic Chicken. International Journal of Current Microbiology and Applied Sciences, 7(8): 3012-3022. DOI: https://www.doi.org/10.20546/ijcmas.2018.708.320

Raue R, Gerlach H, and Muller H (2005). Phylogenetic analysis of the hexon loop 1 region of an adenovirus from psittacine birds supports the existence of a new psittacine adenovirus (PsAdV). Archive of Virology, 150: 1933-1943. DOI: https://www.doi.org/10.1007/s00705-005-0578-x

Schachner A, Matos M, Grafl B, and Hess M (2018). Fowl adenovirus-induced diseases and strategies for their control-a review on the current global situation. Avian Pathology, 47: 111-126. DOI: https://www.doi.org/10.1080/03079457.2017.1385724

Shah MS, Ashraf A, Khan MI, Rahman M, Habib M, Chughtai MI, and Qureshi JA (2017). Fowl adenovirus: History, emergence, biology, and development of a vaccine against hydropericardium syndrome. Archive of Virology, 162: 1833-1843. DOI: https://www.doi.org/10.1007/s00705017-3313-5

Shaib H, Ramadan N, Mahmoud G, Nassif G, and Chedid S (2017). Outbreak of inclusion body hepatitis causing Adenovirus in Lebanese Broiler flocks. EC Microbiology, 13: 92-101. Available at: https://www.ecronicon.com/ecmi/pdf/ECMI-13-00424.pdf

Soumyalekshmi S, Ajith M, Meshram C, and Technology (2014). Isolation of fowl adenovirus in chicken embryo liver cell culture and its detection by hexon gene-based PCR. Indian Journal of Scientific Research, 2: 33-36. Available at: http://www.indjsrt.com/admin/UploadFiles/6-31.pdf

Steer PA, Sandy JR, O'rourke D, Scott PC, Browning GF, and Noormohammadi AH (2015). Chronological analysis of gross and histological lesions induced by field strains of fowl adenovirus serotypes $1,8 \mathrm{~b}$, and 11 in one-day-old chickens. Avian Pathology, 44: 106-113. DOI: https://www.doi.org/10.1080/03079457.2015.1007919

Suohu, Sedeneinuo; Rajkhowa, Tridib Kumar 2021 Prevalence and Molecular Diagnosis of Hydropericardium Hepatitis Syndrome in the Poultry Population of Mizoram, India. Indian Journal of Animal Research. 55 (1): 96-100. DOI: https://www.doi.org/10.18805/ijar.B-3923

Suvarna KS, Layton C, and Bancroft JD (2018). Bancroft's theory and practice of histological techniques E-Book, Elsevier Health Sciences. Available at: http://library.iautmu.ac.ir/file/download/page/1557923707-105-bancroft-s-theory-and-practice-of-histological-techniques-8th-edition-kim-ssuvarna-frcpath-christopher-9780702068645-elsevier-2019-574-209.pdf 